\title{
Educação em saúde sobre antimicrobianos para usuários de Unidades Básicas de Saúde
}

\author{
Health education on antimicrobials to Basic Health Units users
}

\author{
Juan Carlos Campos do Nascimento ${ }^{1}$ \\ Miriam Sofia Duarte Barreto Ramos ${ }^{2}$ \\ Juliana Félix de Melo ${ }^{3}$
}

\section{RESUMO}

O presente relato tem como objetivo descrever a experiência vivenciada por acadêmicos de medicina no desenvolvimento e na execução de atividades de educação em saúde sobre o uso correto de antimicrobianos junto a usuários de Unidades Básicas de Saúde na cidade de Parnaíba, Piauí. As atividades educativas foram realizadas em seis unidades, no período entre abril e dezembro de 2019, por dois estudantes do curso de medicina da Universidade Federal do Delta do Parnaíba. Os graduandos desenvolveram um jogo do tipo quiz e um folder informativo sobre o uso correto dos antimicrobianos e passaram, de forma lúdica, informações importantes sobre esse tema à comunidade. Tais atividades oportunizaram aos discentes envolvidos a aplicação do conhecimento científico para fora do ambiente acadêmico, impactando positivamente na saúde dos indivíduos. Foi percebido o quanto a falta de informação pode contribuir para hábitos nocivos. Além do mais, a realização deste trabalho possibilitou o aprimoramento dos conhecimentos sobre o tema, o incentivo à coletividade e estímulo à criatividade dos estudantes.

Palavras-chave: Promoção da Saúde. Farmacorresistência bacteriana. Automedicação.

\section{ABSTRACT}

This report aims to describe medical students' experience on the development and execution of health education activities about the correct use of antimicrobials for Basic Health Unit users from six units in the city of Parnaíba, State of Piaui, between April and December 2019 by two medical students from Federal University of the Delta do Parnaíba. The undergraduates developed a quiz game and an informational folder about the correct use of antimicrobials and gave, in a ludic way, important information on the topic for the community. Health education activities with users provided medical students with the opportunity of applying scientific knowledge outside the academic environment, positively impacting on the health of individuals. The students realized how much the lack of information can contribute to harmful health behaviors. In addition, carrying out the activities improved students' knowledge on the topic, encouraged collective work and stimulated creativity.

Keywords: Health promotion. Drug resistance bacterial. Self medication.

\footnotetext{
1 Graduando em Medicina na Universidade Federal do Piauí, Brasil; membro da Liga de Oncologia do Delta (Lionco), bolsista no Projeto de Educação em Saúde sobre o uso correto de antibióticos como estratégia de controle da resistência bacteriana (juanjccn@live.com).

2 Graduanda em Medicina na Universidade Federal do Piauí, Brasil; membro do Grupo de Pesquisa em Avaliação da Saúde Pública (miriamdbarreto@hotmail.com).

${ }^{3}$ Doutora em Medicina Tropical pela Universidade Federal de Pernambuco, Brasil, com período co-tutela na Universitè de Technologie de Compiègne, França; estágio pós-doutoral no Institut Cochin, França; professora adjunta do curso de Medicina da Universidade Federal do Delta do Parnaíba, Piauí, Brasil (julemelo@hotmail.com).
} 


\section{INTRODUÇÃO}

O advento de medicamentos antimicrobianos, desde a descoberta da penicilina, por Alexander Fleming, tem contribuído indiscutivelmente no manejo das doenças infecciosas, reduzindo complicações e a mortalidade. Entretanto, com o passar dos anos e com o aumento no uso dos antibióticos, muitos microrganismos têm desenvolvido resistência, dificultando o tratamento, aumentando assim a mortalidade (KAUR, 2018).

Tal crise de resistência aos antimicrobianos tem sido associada ao uso desordenado dos medicamentos, erros de prescrição, contaminação ambiental e da cadeia alimentar e, também, à falta de desenvolvimento de novos fármacos (PONTES et al., 2018). A simples existência de compostos antibióticos no meio ambiente já impõe pressão seletiva sobre bactérias que apresentam genes responsáveis pela expressão dos mecanismos de resistência, o que pode ser agravado pelo uso não eficiente dos antibióticos (ALEKSHUN; LEVY, 2007).

Além dos fatores não controláveis relacionados à resistência bacteriana, em um contexto geral da automedicação no Nordeste, estudos apontam que ela é exercida por $23 \%$ da população, havendo evidências de que essa prática também ocorre com os antibióticos, apesar da necessidade de receita médica para a sua aquisição (ARRAIS et al., 2016).

Vale salientar que o uso inadequado de fármacos antimicrobianos e os malefícios da resistência bacteriana não são problemas recentes. Já na década de 1970, Scheckler e Bennet (1970), bem como Kunin, Tupasi e Craig (1973), observaram que entre 30 e 50 por cento dos pacientes em uso de antimicrobianos não apresentavam sinais infecciosos compatíveis. Em uma análise feita por Jogerst e Dippe (1981) houve evidência de uso inadequado em mais de metade das prescrições desses fármacos. No início dos anos 2000, a União Europeia estimava cerca de 25.000 mortes decorrentes da resistência bacteriana, com custos associados estimados em torno de 1,5 bilhão de euros por ano (ECDPC/EMA, 2009). À mesma época, estudos realizados nos Estados Unidos da América demonstravam um custo adicional de mais de 18 milhões de dólares anuais, com uma média de aproximadamente nove dias no tempo de internação de um paciente em caso de uma bactéria resistente (ROBERTS et al., 2009).

Dessa forma, os antimicrobianos não devem ser vistos apenas como medicamentos com alto valor para a saúde pública, mas como um recurso não renovável, que tem sua eficácia reduzida em cenários de uso inadequado, o que requer ações governamentais de avaliação, 
inspeção, fiscalização, treinamento, desenvolvimento científico e participação social para a prevenção e redução da resistência bacteriana (LAZOVSKI et al., 2017).

Dentre as diversas estratégias recomendadas para a prevenção da resistência bacteriana, as atividades educativas com enfoque na sensibilização e compreensão desse tema estão entre os objetivos específicos do Plano Nacional para a Prevenção e o Controle da Resistência Microbiana nos Serviços de Saúde (BRASIL, 2017). Além disso, a automedicação é apontada como um dos mecanismos de uso indiscriminado dos antibióticos, o que demonstra a necessidade e importância das ações de educação em saúde como ferramentas no combate à resistência bacteriana (DEL FIOL et al., 2010). Vale salientar que a educação em saúde se apresenta como ferramenta valiosa para a promoção da saúde, capaz de transformar práticas e comportamentos individuais, impactando positivamente na saúde e qualidade de vida dos indivíduos (LOPES et al., 2010).

Esta ação foi idealizada frente à importância do controle da resistência bacteriana para a saúde pública em um cenário de aquisição facilitada de antibióticos sem a receita médica em algumas farmácias da cidade. Demonstrou-se relevante, já que visou a promoção da saúde, com potencial modificador de um dos pilares do uso incorreto dos antibióticos, a automedicação. Informações capazes de impactar positivamente a saúde dos indivíduos e, de forma mais ampla, a saúde pública, mostraram-se necessárias nesse contexto.

Sendo assim, este estudo teve o objetivo de descrever a experiência vivenciada por acadêmicos de Medicina no desenvolvimento e execução de atividades de educação em saúde sobre o uso correto de antimicrobianos com usuários de Unidades Básicas de Saúde (UBS) na cidade de Parnaíba, Piauí.

\section{RELATO DA EXPERIÊNCIA}

Este é um estudo descritivo, qualitativo, que aborda a experiência de dois discentes do curso de Medicina da Universidade Federal do Delta do Parnaíba (UFDPar), cujo registro fez parte das atividades programadas do projeto de extensão intitulado "Atividade educativa sobre o uso correto dos antimicrobianos como estratégia de controle da resistência bacteriana". Sendo assim, foram realizados o levantamento bibliográfico sobre o tema, a escolha da metodologia 
a ser utilizada durante a atividade e os ritos administrativos relacionados à autorização para realizar as atividades nas UBS.

O projeto foi submetido à Secretaria da Atenção Básica do Município de Parnaíba-PI. Após sua avaliação, a secretaria emitiu uma declaração permitindo a realização da atividade nas unidades listadas. Em seguida, houve o processo de apresentação da atividade para os coordenadores de cada unidade, bem como a organização dos dias de execução das atividades. Esse trabalho se enquadra no item VIII do artigo $1^{\text {o }}$ da Resolução $\mathrm{n}^{\circ} 510$, de 7 de abril de 2016, do Conselho Nacional de Saúde, dispensando assim a submissão ao Comitê de Ética em Pesquisa (CEP).

Como metodologia escolhida optou-se por uma atividade lúdica de 20 minutos em cada UBS participante, utilizando-se de um jogo interativo. Para auxiliar na discussão dos conteúdos, foram empregados um folder educativo, entregue a cada usuário da UBS no início da atividade, bem como imagens selecionadas, em formato de banner.

O jogo baseava-se em uma espécie de quiz, composto de cinco perguntas subjetivas e cinco respostas norteadoras, que estavam dispostas em "cartões-resposta". Segundo Yonekura e Soares (2010), esse tipo de atividade consiste em uma estratégia lúdica que serve de gancho para as discussões sobre o tema. Os cartões-resposta eram distribuídos conforme a disposição dos usuários em participar da atividade. Em seguida, uma pergunta era sorteada com o auxílio de um dado comum (seis lados). A pergunta correspondente era feita pelos estudantes e os usuários respondiam conforme suas vivências. Posteriormente, o portador do cartão-resposta fazia a leitura, sendo então complementado pelos discentes e, dessa forma, todo o conteúdo previsto era então apresentado.

De uma forma geral, as perguntas compreendiam o conhecimento dos usuários sobre o que seria um antibiótico, se já haviam feito uso dos mesmos, dos sintomas/doenças motivadoras do uso, dos malefícios do uso incorreto e da resistência bacteriana.

Foram realizadas 22 visitas nas seis UBS previamente selecionadas para as atividades, no período entre abril e dezembro de 2019, na cidade de Parnaíba-PI. Essa ação atingiu o número estimado de 500 usuários. As atividades ocorriam na sala de espera, partindo do entendimento desse ambiente como propício à troca de saberes, possibilitando interações capazes de impactar positivamente na saúde dos indivíduos e se mostrando de grande valia para a educação em saúde (LIMEIRA et al., 2014). 
O trabalho foi avaliado de forma qualitativa por meio de relatórios dos discentes a cada visita que permitiram identificar e elencar o conhecimento prévio e o nível de aprendizado dos participantes sobre os assuntos abordados.

A experiência criativa possibilitou aos discentes a aplicação dos conhecimentos adquiridos e a adaptação de tais conteúdos aos indivíduos-alvo da atividade, contribuindo, assim, para o raciocínio crítico e para o reconhecimento da importância de tal adaptação para o entendimento da mensagem por parte dos usuários das UBS. Tal processo também oportunizou aos discentes o reconhecimento do lúdico para além do universo infantil (CYRINO et al., 2016).

No decorrer das atividades educativas, o antibiótico amoxicilina foi o mais comumente relatado como alvo da automedicação, seguido da sulfa e da cefalexina, em situações envolvendo "dor de garganta", "infecção urinária" e "diarreia". Esses resultados corroboram com outros estudos, nos quais amoxicilina foi o antibiótico mais usado e os motivadores mais comuns foram a "dor de garganta" e a "infecção urinária" (ZHU et al., 2016; SANTOS, 2017).

Além disso, a dificuldade de acesso aos serviços de saúde como motivador da automedicação frente a um cenário de doença foi comumente posto em discussão pelos usuários. Nesse contexto, os achados do estudo corroboram com outros levantamentos, nos quais a automedicação permanece presente na população, dentre outros motivos, devido ao acesso precário aos serviços de saúde (ARRAIS et al., 2016). Os usuários reconheciam/afirmavam a facilidade encontrada em algumas farmácias da cidade para a compra de antibióticos sem receita médica. A ilegalidade desse ato foi salientada nas atividades, explicando que as farmácias não devem vender antibióticos sem a prescrição dos profissionais habilitados (BRASIL, 2010).

Apesar do relato do uso irrestrito de antibióticos, alguns usuários conseguiam explicar o que é a resistência bacteriana. No entanto, a grande maioria desconhecia os malefícios do uso incorreto dos antibióticos e sua relação com a resistência bacteriana (PONTES et al., 2018). Ainda que o uso dos antibióticos seja restrito, a população do estudo se vale desses fármacos baseada em experiências, seja uma indicação médica anterior ou de alguém próximo que já fez uso de tais medicamentos e obteve a melhora do quadro que sentia no momento (DOMINGUES et al., 2017). Sob essa ótica, foi possível perceber o quanto a falta de 
informação pode afetar as escolhas dos indivíduos, trazendo à tona os atravessamentos envolvidos no uso indevido de antibióticos por parte da população.

\section{CONSIDERAÇÕES FINAIS}

A experiência se mostrou de extrema relevância, pois possibilitou aos acadêmicos o reconhecimento da importância da educação em saúde frente à emergência da resistência bacteriana e do papel da promoção da saúde na construção de autonomia e bons hábitos. Além disso, permitiu-lhes compreender que o conteúdo científico pode extrapolar o ambiente acadêmico, produzindo conhecimento para além dos muros institucionais.

A atividade oportunizou o conhecimento das dificuldades de acesso à saúde e a saberes relacionados aos antibióticos, possibilitando a reflexão sobre como a realidade local tem poder de fazer com que a população adote medidas não seguras e com potencial de danos futuros à sua saúde. Dessa forma, a experiência relatada, além dos benefícios percebidos para o controle da emergência da resistência bacteriana, dotou os discentes de informações valiosas para a prática profissional.

Dentro desse contexto, foi possível perceber o impacto positivo da atividade em um dos motivadores da automedicação: a falta de informação sobre os malefícios da prática. Já em relação à dificuldade de acesso aos serviços de saúde, entendemos a complexidade do problema, que deve ser abordado tanto pela gestão local, com a ampliação do horário de atendimento e o provimento de profissionais, como por todos os profissionais da atenção básica, com um acolhimento eficaz, para que os usuários não precisem recorrer ao uso inadvertido de medicamentos.

Os resultados dessa ação devem servir de subsídio para outros trabalhos e novas ações são necessárias para enfrentar esse problema de automedicação e resistência bacteriana. Sendo assim, esse estudo traz como perspectivas a continuidade da ação em outras UBS da cidade de Parnaíba-PI e a realização dessas atividades voltadas para os estudantes do ensino fundamental e ensino médio. 


\section{REFERÊNCIAS}

ALEKSHUN, M. N.; LEVY, S. B. Molecular mechanisms of antibacterial multidrug resistance. Cell, Cambridge, v. 128, n. 6, p. 1037-1050, 2007. Disponível em: https://pubmed.ncbi.nlm.nih.gov/17382878/. Acesso em: 4 set. 2020.

ARRAIS, P. S. D. et al. Prevalência da automedicação no Brasil e fatores associados. Rev. de Saúde Pública, São Paulo, v. 50, suppl. 2, p. 13, 2016. Doi: 10.1590/S15188787.2016050006117. Disponível em: http://www.scielo.br/scielo.php?script=sci_arttext\&pid=S003489102016000300311\&lng=en. Acesso em: 4 set. 2020.

BRASIL, Ministério da Saúde. Agência Nacional de Vigilância Sanitária. Plano Nacional para a Prevenção e o Controle da Resistência Microbiana nos Serviços de Saúde. Brasília: Ministério da Saúde, 2017. Disponível em: https://www20.anvisa.gov.br/segurancadopaciente/index.php/publicacoes/item/planonacional-para-a-prevencao-e-o-controle-da-resistencia-microbiana-nos-servicos-de-saude. Acesso em: 18 set. 2020.

BRASIL. Ministério da Saúde. Agência Nacional de Vigilância Sanitária. Resolução-RDC no 44, de 26 de outubro de 2010, que dispõe sobre o controle de medicamentos à base de substâncias classificadas como antimicrobianos, de uso sob prescrição médica, isoladas ou em associação e dá outras providências. Brasília: Ministério da Saúde, 2010. Disponível em: https://bvsms.saude.gov.br/bvs/saudelegis/anvisa/2010/res0044_26_10_2010.html\#: :text=Di sp\%C3\%B5e\%20sobre $\% 20 \mathrm{o} \% 20$ controle $\% 20$ de,que $\% 201$ he $\% 20$ confere $\% 20 \mathrm{o} \% 20$ art. Acesso em: 2 out. 2020.

CYRINO, R.S. et al. Atividades lúdicas como estratégia de educação em saúde com idosos. Revista Ciência em Extensão, São Paulo, v.12, n. 3, p. 154-163, 2016. Disponível em: https://ojs.unesp.br/index.php/revista_proex/article/view/1324/1260. Acesso em: 25 set. 2020.

DEL FIOL, F. S. et al. Perfil de prescrições e uso de antibióticos em infecções comunitárias. Rev. Soc. Bras. Med. Trop., Uberaba, v. 43, n. 1 p. 68-72, 2010. Doi: 10.1590/S003786822010000100015. Disponível em: http://www.scielo.br/scielo.php?script=sci_arttext\&pid=S003786822010000100015\&lng=en. https://doi.org/10.1590/S0037-86822010000100015. Acesso em: 20 set. 2020.

DOMINGUES, P. H. F. et al. Prevalência e fatores associados à automedicação em adultos no Distrito Federal: estudo transversal de base populacional. Epidemiol. Serv. Saúde, Brasília, v. 26, n. 2, p. 319-30, 2017. Doi: 10.5123/S1679-49742017000200009. Disponível em: http://www.scielo.br/scielo.php?script=sci_arttext\&pid=S223796222017000200319\&lng=pt. http://dx.doi.org/10.5123/s1679-49742017000200009. Acesso em: 2 out. 2020.

\section{EUROPEAN CENTRE FOR DISEASE PREVENTION AND CONTROL. The bacterial} challenge: time to react... Stockholm: ECDPC/EMA, 2009. Doi: doi 10.2900/2518. Disponível em:

http://www.ecdc.europa.eu/en/publications/Publications/Forms/ECDC_DispForm.aspx?ID=4 44. Acesso em: 4 set. 2020. 
JOGERST, G. J.; DIPPE, S. E. Antibiotic use among medical specialties in a communityhospital. JAMA, Chicago, v. 245, p. 842-846, 1981. Doi:

doi:10.1001/jama.1981.03310330032020. Disponível em:

https://jamanetwork.com/journals/jama/article-abstract/373888. Acesso em: 18 set. 2020.

KAUR, H. The need of time: development of new antimicrobials [editorial]. Curr Top Med

Chem., Sharjah, v. 18, n. 1, p. 2, 2018. Doi: 10.2174/156802661801180322101958. Disponível em: https://pubmed.ncbi.nlm.nih.gov/29598813/. Acesso em: 4 set. 2020.

KUNIN, C. M.; TUPASI, T.; CRAIG, W. A. Use of antibiotics: a brief exposition of the problem and some tentative solutions. Annals of Internal Medicine, Philadelphia, v. 79, n. 4, p. 555-560, 1973. Doi: doi.org/10.7326/0003-4819-79-4-555. Disponível em:https://www.acpjournals.org/doi/pdf/10.7326/0003-4819-79-4-555. Acesso em: 4 set. 2020.

LAZOVSKI, J. et al. Estrategia de control de la resistencia bacteriana a los antimicrobianos en Argentina. Rev. Panam. Salud Publica, Whashington, v. 41, n. 88, p. 1-5, 2017. Doi: 10.26633 / RPSP.2017.88. Disponível em: https://www.ncbi.nlm.nih.gov/pmc/articles/PMC6660862/. Acesso em: 6 out. 2020.

LIMEIRA, M. E. O. et al. Sala de espera como ferramenta para educação em saúde na atenção básica. RBCS, João Pessoa, v. 18, p. 59-62, 2014. Disponível em: https://periodicos.ufpb.br/ojs/index.php/rbcs/article/view/21238. Acesso em: 25 set. 2020.

LOPES, M.S.V. et al. Análise do conceito de promoção da saúde. Texto \& Contexto Enfermagem, Florianópolis, v. 19, n. 3, p. 461-468, 2010. Doi: 10.1590/S010407072010000300007. Disponível em:

http://www.scielo.br/scielo.php?script=sci_arttext\&pid=S010407072010000300007\&lng=en. https://doi.org/10.1590/S0104-07072010000300007. Acesso em: 6 out. 2020 .

PONTES, D. S. et al. Genetic mechanisms of antibiotic resistance and the role of antibiotic adjuvants. Curr Top Med Chem., Sharjah, v.18, n. 1, p. 42-74, 2018. Doi: doi: 10.2174/1568026618666180206095224. Disponível em: https://pubmed.ncbi.nlm.nih.gov/29412107/. Acesso em: 4 set. 2020.

ROBERTS, R. et al. Hospital and societal costs of antimicrobial resistant infections in a Chicago Teaching Hospital: implications for antibiotic stewardship. Clin Infect Dis., Oxford, v. 49, n. 8, p. 1175-1184, 2009. Doi: 10.1086/605630. Disponível em: https://pubmed.ncbi.nlm.nih.gov/19739972/. Acesso em: 18 set. 2020.

SANTOS, J. R. dos. Avaliação da procura de antibióticos sem receita médica por clientes de três farmácias no município de Cruz das Almas - Bahia. 2017. 60 f. Trabalho de Conclusão de Curso (Graduação em Farmácia) - Faculdade Maria Milza, Governador Mangabeira, 2017. Disponível em: http://famamportal.com.br:8082/jspui/bitstream/123456789/422/1/TCC\%20FINAL\%20PRO NTO\%20PRA\%20ENTREGAR.pdf. Acesso em: 25 set. 2020.

SCHECKLER, W. E.; BENNETT, J. V. Antibiotic usage in seven community hospitals. JAMA, Chicago, v. 213, n. 2, 1970. Disponível em: 
https://jamanetwork.com/journals/jama/article-abstract/355427

doi:10.1001/jama.1970.03170280024004. Acesso em: 4 de set. 2020.

YONEKURA, T.; SOARES, C. B. O jogo educativo como estratégia de sensibilização para coleta de dados com adolescentes. Rev. Latino-Am. Enfermagem, Ribeirão Preto, v. 18, n. 5, p. 1-7, 2010. Doi: 10.1590/S0104-11692010000500018. Disponível em:

scielo.br/pdf/rlae/v18n5/pt_18. Acesso em: 18 set. 2020.

ZHU, X. et al. Self-medication practices with antibiotics among chinese university students. Public Health., [s.l.], v. 130, p.78-83, 2016. Doi: 10.1016/j.puhe.2015.04.005. Disponível em: https://www.sciencedirect.com/science/article/pii/S003335061500164X?via\%3Dihub doi: 10.1016/j.puhe.2015.04.005. Acesso em: 25 set. 2020.

Submetido em 25 de janeiro de 2021. Aprovado em 21 de abril de 2021. 